ORIGINAL ARTICLE

\title{
Impact of occupational stress and other psychosocial factors on musculoskeletal pain among Chinese offshore oil installation workers
}

\author{
W Q Chen, I T-S Yu, T W Wong
}

Occup Environ Med 2005;62:251-256. doi: 10.1136/oem.2004.013680

See end of article for authors' affiliations

....................

Correspondence to: DrI Yu, Department of Community \& Family Medicine, The Chinese University of Hong Kong,
$4 / F$, School of Public Health, Prince of Wales Hospital, Shatin, NT, Hong Kong; iyu@cuhk.edú.hk

Accepted 6 January 2005

\begin{abstract}
Aims: To explore the relation between psychosocial factors and musculoskeletal pain in Chinese offshore oil installation workers.

Methods: Half of all offshore workers (being a representative sample) in a Chinese oil company were invited to complete a self-administered questionnaire providing information on sociodemographic characteristics, occupational stressors, type A behaviour, social support, coping style, health related behaviour, past injuries, and musculoskeletal pain. Factor analysis was used to identify the sources of occupational stress and the domains of type A behaviour and coping style. Logistic regression analyses were used to study the relations between psychosocial factors and musculoskeletal pain in each body region.

Results: The prevalence of musculoskeletal pain over the previous 12 months varied between $7.5 \%$ for elbow pain and $32 \%$ for low back pain; $56 \%$ workers had at least one complaint. Significant associations were found between various psychosocial factors and musculoskeletal pain in different body regions after adjusting for potential confounding factors. Occupational stressors, in particular stress from safety, physical environment, and ergonomics, were important predictors of musculoskeletal pain, as was coping by eating behaviour.

Conclusions: These observations supported the widely accepted biopsychosocial model of musculoskeletal disorders and suggested that in future studies of work related musculoskeletal disorders, psychosocial factors must be given due consideration.
\end{abstract}

M usculoskeletal pain, in particular low back pain, is one of the most common occupational health problems and accounts for a large number of workers' compensation days and disability in modern industrialised societies. ${ }^{1}$ It is believed that occupational musculoskeletal pain is caused by multiple factors, generally categorised into mechanical and psychosocial ones. Various mechanical factors have been found to be associated with pain in different body regions. ${ }^{2-4}$ Heavy physical work, heavy or frequent manual operations, repeated rotation of the trunk, whole body vibration, and prolonged sitting were positively associated with low back pain..$^{5-8}$ Working with hands at or above shoulder level, flexion of the neck, static contractions, monotonous or repetitive work with arms, high working pace, and unsuitable work place were responsible for neck and shoulder pain. ${ }^{9}{ }^{10}$

Psychosocial factors at work have also been shown to play important roles in the development of musculoskeletal pain. Important psychosocial factors included work demands and decision latitude, ${ }^{11}{ }^{12}$ symptoms of stress, ${ }^{13}$ social support, ${ }^{14}$ type A behaviour, ${ }^{15}$ and psychological distress. ${ }^{16}$ After reviewing 59 relevant studies, Bongers and colleagues ${ }^{17}$ concluded that monotonous work, high perceived workload, time pressure, low control on the job, lack of social support from colleagues, and stress symptoms were related to musculoskeletal problems. Carayon and colleagues ${ }^{18}$ reviewed work organisation, job stress, and work related musculoskeletal disorders, and concluded that work organisation and psychosocial factors at work could contribute to upper extremity disorders. They further indicated that work organisation and ergonomic factors might interact to affect the musculoskeletal system.
Offshore oil production is generally regarded as a stressful occupation. Apart from receiving stressors that are common to most workplaces, they are also exposed to stressors that are specific to the offshore setting. ${ }^{19-21}$ The physical stressors include noise, vibration, poor lighting and ventilation, confined living and working space, adverse offshore weather conditions, long working hours, and shift work, etc. Psychosocial stressors cover job characteristics (work load, variety, clarity, control), perceived risk (fire, explosion, blow out, travelling by helicopter or ships, etc), job insecurity, work-family interface, and the lack of certain types and sources of social support.

Norman and colleagues ${ }^{22}$ found that musculoskeletal disorders were the second top cause for medical evacuations among offshore oil workers in the North Sea from 1976 to 1984. This implied that musculoskeletal pain would be an important health problem among the offshore oil workers. However, most studies on work related musculoskeletal pain have mainly focused on onshore occupational groups, and very little is known about the situation in offshore oil workers. We conducted a comprehensive study on occupational stress and its influence on health of Chinese offshore oil installation workers. We intend to describe the prevalence of musculoskeletal pain and explore the impact of occupational stress and other work related psychosocial factors.

\section{SUBJECTS AND METHODS}

\section{The company and study subjects}

The study subjects were offshore workers from an offshore oil company in South China, which employed about 1100 offshore oil workers working on five installations. The offshore workers were divided into two groups which took 


\section{Main messages}

- Musculoskeletal complaints were not uncommon among Chinese offshore oil installation workers, given the highly selective nature of the workforce. More than half of them had at least one complaint over a 12 month period. Low back pain was the most common and serious problem.

- Occupational stressors, in particular stress from safety, physical environment, and ergonomics, were important predictors of musculoskeletal pain.

- Maladaptive eating behaviour was the most important coping strategy and was significantly associated with musculoskeletal pain in six of the nine body parts.

- For social support, the only positive association was between poor instrumental support from supervisors and pain in the wrists/hands.

- Type A behaviour pattern did not have an independent effect on musculoskeletal pain after adjusting for other covariates.

rotations of four weeks to work on the platforms at sea. At any one time around half of the offshore workers would be working offshore, the remainder staying onshore. To achieve smooth operations on the platforms, there were fixed proportions of senior and junior workers in each shift group. The job positions on each platform were also fixed. The onshore and offshore groups were broadly the same in terms of their ranking, work experience, age structure, and distribution of job categories. We attempted to survey all workers in one group $(\mathrm{n}=581)$ during their onshore rotation, of which $561(96.6 \%)$ completed the questionnaire.

\section{The questionnaire}

All our study subjects were asked to complete a selfadministered questionnaire collecting information on sociodemographic characteristics, occupational stress, type A behaviour, social support, coping style, health related behaviour, injuries in the past year, and musculoskeletal pain. Before administering the questionnaire, several trained investigators were present to explain to all the participants the aims of study, the contents of the questionnaire, and how to complete it. As the workers filled in the questionnaires, the investigators were present to answer any quires. They also checked all questionnaires for missing data and followed up to obtain the relevant information. To minimise information bias and to ensure that workers would not hide sensitive information, all questionnaires were anonymous. The workers were reassured that the data would be used for research purposes only and that the questionnaires would not be released to the company. No management staff of the company was present during the survey.

Occupational stress was measured by the Occupational Stress Scale (OSS), developed from the questionnaire used in previous studies of offshore workers in the UK. ${ }^{23-25}$ The validity and reliability of our instrument have been assessed before. $^{26}$

Type A behaviour pattern (TABP) was assessed with a revised version of Bortner Scale, ${ }^{27-29}$ which consisted of 14 bipolar items with descriptors to reflect type A and type B behaviour placed at opposite ends of an 11 point scale. To facilitate data analysis, we adopted a unidirectional scale, a higher score indicating a tendency towards type A behaviour.

\section{Policy implications}

- Despite the high level of automation in the production processes, musculoskeletal pain is not uncommon among Chinese offshore workers. Occupational health service providers should be well aware of its presence.

- The associations between psychosocial factors and musculoskeletal pain suggested that psychosocial factors must be given due considerations when studying or managing musculoskeletal complaints.

- As the causal relation between psychosocial factors and musculoskeletal pain could not be confirmed in this cross-sectional study, prospective cohort studies would be needed to confirm or refute the causal links.

Two types of social support (instrumental support and emotional support) from four sources (supervisors, colleagues, wife, and friends) were assessed by rating with a four point Likert scale $(1=$ never, $2=a$ few, $3=$ sometimes, and $4=$ often). In the further analysis, the social support of each type and source was dichotomised into "strong support" (often) and "lack of support" (never, a few, or sometimes).

The coping scale was adopted from the occupational stress indicator ${ }^{23}$ coping questionnaire and Hingley and Cooper's coping questionnaire. ${ }^{30}$ It consisted of 20 coping responses rated on a six point Likert scale (ranging from "never used" to "almost used every day").

The health related behaviours included smoking, alcohol consumption, and physical exercise during leisure time.

Information on the prevalence of musculoskeletal complaints in the different body regions during the past seven days and past 12 months was obtained using the standardised Nordic questionnaire. ${ }^{31}$

\section{Data analyses}

First, factor analysis with a varimax rotation was used to identify the sources of occupational stress and the domains of TABP and coping style. ${ }^{32}$ A factor was included when the eigenvalue was greater than one. Within each factor, the items with the highest factor loading were then identified and loaded onto this factor. A factor loading greater than 0.40 was regarded as important. Then, the relations between musculoskeletal pain in each body region and each item of occupational stress and other psychosocial factors at work were analysed, using multiple forward stepwise logistic regression analysis with adjustment for age, educational level, marital status, duration of offshore employment, job title, and history of injury in the past 12 months. Although we did not have any reason to believe that musculoskeletal pain in different body parts could be affected by different psychosocial variables, as other risk factors (personal characteristics, physical factors, etc) associated with musculoskeletal pain in different body parts could be different, the influence of different psychosocial variables might differ after adjusting for these covariates in the multivariate analyses. All factors thought to affect musculoskeletal pain, other than psychosocial factors, were entered together in the first step. The psychosocial factors were selected on the basis of a forward stepwise procedure during a second step. The criterion for inclusion was a p value of $<0.05$ while the criterion for exclusion was a $\mathrm{p}$ value of $\geqslant 0.10$. In the logistic regressions, for each body region, the subjects with musculoskeletal pain in that body region during the past 12 months were compared with those free from musculoskeletal pain in all the nine body regions. 


\section{RESULTS}

The basic characteristics of the workers were reported in detail in an earlier report. ${ }^{26}$ All workers were males and had a mean age of 32.43 (SD 8.65) and a mean platform working experience of 8.24 years (SD 7.39). Over $77 \%$ had received at least high school education; $68.4 \%$ were married.

\section{Sources of stress}

From factor analyses, nine sources of occupational stress were identified and have been reported previously. ${ }^{33}$ These were "physical environment of workplace", "safety", "interface between job and family/social life", "career and achievement", "organisational structure", "living environment", "ergonomics", "management problem and relationship with others at work" and "managerial role" in descending order of importance. They explained $62.5 \%$ of the total variance.

\section{Type A behaviour pattern (TABP)}

Factor analysis of the 14 characteristics of TABP yielded two domains that explained $36.27 \%$ of the total variance. One domain reflected the traits of impatience and hard driving, while the other involved speed and ambition.

\section{Coping style}

From factor analysis of 20 items of coping style, five domains with eigenvalue over 1 were identified, which explained $51.03 \%$ of the total variance. According to the context of the items loading on each factor, they were defined as: "eating behaviour", "external/social behaviour", "escaping/abreaction behaviour", "positive attitude/denying behaviour" and "internal behaviour".

\section{Musculoskeletal pain and its association with occupational stress, TABP, social support, coping style, and health related behaviours}

Table 1 presents the prevalence of musculoskeletal pain by body regions in the past 12 months and the past week, as well as their impact on the workers' daily life activities. Low back pain was the most common and serious musculoskeletal health problem for this group of workers, and elbow pain was the least important. A total of 316 respondents (56.3\%) complained of one or more symptoms; $124(22.1 \%)$ had one symptom, $77(13.7 \%)$ had two, $31(5.5 \%)$ had three, 31 $(5.5 \%)$ had four, and $50(9.4 \%)$ had five or more symptoms.

Table 2 shows the results of the multivariate logistic regression analyses with adjustments for age, educational level, marital status, duration of working offshore, job title, and the history of work related injury in the past year. Pain in the neck, shoulders, upper back, knees, and ankles/feet was increased by several perceived sources of occupational stress and eating coping style. In addition, upper back pain was also increased by the escaping/abreaction coping style. On the other hand, pain in the knees and ankles/feet was decreased by managerial role. Low back pain was only affected by occupational stressors. Elbow pain was related to stress from the physical environment and the coping styles of "eating" and "escaping/abreaction". Pain in the wrists/hands was increased by stress from the living environment on platforms and ergonomics, as well as the external/social coping behaviour. Pain in the hips/thighs was increased by ergonomics stress and the internal coping style. Important psychosocial risk factors that affected more than half of the body regions included stress from safety, physical environment, and ergonomics, as well as coping by eating behaviour. In addition to the psychosocial factors, neck pain was also significantly positively associated with the following job types: drilling workers, electricians, mechanics, material and power workers, with odds ratios (OR) ranging between 2.45 and 3.70. Elbow pain was significantly increased in electricians (OR 4.02) and power workers (OR 8.03), whereas low back pain was significantly less among managers (OR 0.34). A history of injury in the past 12 months was significantly associated with an increased risk of pain in the spine, including the neck, and upper and low back regions (OR $1.82-2.13)$.

\section{DISCUSSION}

This was the first comprehensive study on the influence of occupational stress and other psychosocial factors at work on musculoskeletal pain among Chinese offshore oil workers. The results showed that musculoskeletal pain, in particular low back pain, was not uncommon among this group of active workers. Occupational stressors, in particular stress from safety, physical environment, and ergonomics, were important predictors of musculoskeletal pain, as was coping by eating behaviour. Social support and the type A behavioural pattern appeared to be less important.

The prevalence of musculoskeletal pain in this study was in general lower than that reported among workers in other heavy industries, for example, steel workers, ${ }^{34}$ construction workers, ${ }^{35}$ and workers in an automobile assembly plant, ${ }^{3}$ although low back pain was the most common disorder as in the other groups of workers. The lower prevalence might be associated with a high level of automation on oil platforms, as well as the possible healthy worker effect arising from the self-selection of these offshore workers. ${ }^{21}$

\section{Associations between occupational stress and musculoskeletal pain}

Many previous studies on work stress and musculoskeletal disorders focused on work demands, the job decision latitude model, symptoms of stress, dissatisfaction with job, and monotonous work. ${ }^{11-133637} \mathrm{~A}$ few studies revealed that other

Table 1 Prevalence of musculoskeletal complaints by body regions among the 561 Chinese offshore oil installation workers

\begin{tabular}{|c|c|c|c|c|c|c|}
\hline \multirow[b]{2}{*}{ Body region } & \multicolumn{2}{|c|}{ In the past 12 months } & \multicolumn{2}{|c|}{ Impacting activity } & \multicolumn{2}{|c|}{ During the past 7 days } \\
\hline & Cases & $\%$ & Cases & $\%$ & Cases & $\%$ \\
\hline Neck & 140 & 25.0 & 37 & 6.6 & 27 & 4.8 \\
\hline Shoulders & 112 & 20.0 & 31 & 5.5 & 27 & 4.8 \\
\hline Elbows & 42 & 7.5 & 16 & 2.9 & 11 & 2.0 \\
\hline Wrists/hands & 76 & 13.5 & 20 & 3.6 & 11 & 2.0 \\
\hline Upper back & 77 & 13.7 & 20 & 3.6 & 16 & 2.9 \\
\hline Low back & 180 & 32.4 & 56 & 10.0 & 45 & 8.0 \\
\hline Hips/thighs & 47 & 8.4 & 20 & 3.6 & 13 & 2.3 \\
\hline Knees & 113 & 20.1 & 32 & 5.7 & 29 & 5.9 \\
\hline Ankles/feet & 57 & 10.2 & 22 & 3.9 & 15 & 2.7 \\
\hline
\end{tabular}




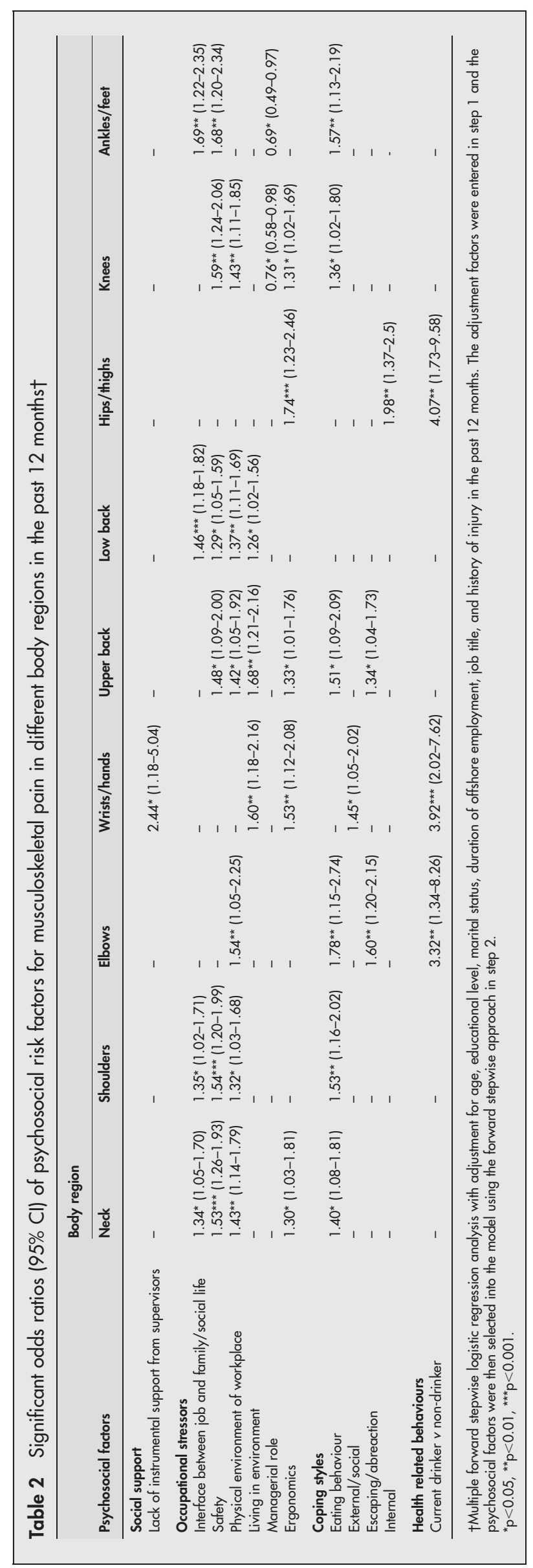

work stress related factors were also related to musculoskeletal pain. Ohlsson and colleagues ${ }^{38}$ showed that a tendency towards stress or worry and a high work strain clearly increased the risk of disorders of the neck or shoulders in the fish processing industry, whereas high stimulation at work was a protective factor. A study among salespersons ${ }^{39}$ indicated that variations in work and the uncertainty of employment prospects were associated respectively with the increased risk of symptoms of neck and the shoulders in the past 12 months.

Our results showed that six of the nine perceived sources of occupational stress were significantly related to musculoskeletal pain in different body regions after adjustment for sociodemographics and the history of work related injuries in the past year. Perceived stress from "interface between job and family/social life", "safety", "physical environment of workplace", "living environment", and "ergonomics" were risk factors for pain in different body regions, whereas perceived stress from "managerial role" was a protective factor for knee and ankles/feet pain.

How does occupational stress affect musculoskeletal disorders? The current explanation is that it might do so through two routes: neuromuscular tension and an increased sensitivity to pain in local areas. ${ }^{217} 18$ Perceived stress increases muscle tension, and if this tension persists for a long period, it may result in musculoskeletal pain. Perceived stress also enhances the perception of musculoskeletal symptoms. Since no data on physical risk factors at work were collected in our study, it was not possible to explore whether perceived stress at work directly, or through interaction with physical risk factors, influenced the development of musculoskeletal pain. Although perceived stresses from "physical environment of workplace" (noise, vibration, and heat) and "ergonomics" (fast pace, work in awkward position for long period, and move or lift heavy objects) were defined as psychosocial risk factors in this study, they might indirectly reflect the physical risks at work. Vibration and ergonomic factors have been reported to be important risk factors for musculoskeletal disorders in many studies. ${ }^{2-4}$ However, the lack of objective measurements on vibration and ergonomic factors in this study prevents us from distinguishing whether they might have led to musculoskeletal pain through direct physical impacts, or as psychosocial risk factors through an indirect path.

The negative associations between perceived stress from "managerial role" and pain in the knees and ankles/feet suggested that physical factors might be important, as the subjects who perceived stress from "managerial role" were mostly managers working in offices and removed from the physical stressors experienced by manual workers, such as heavy physical load, prolonged standing, vibration, etc. These physical stressors have been shown to be risk factors for musculoskeletal disorders..$^{2-4}$

\section{Associations between other psychosocial factors and musculoskeletal pain}

Type A behaviour pattern did not have an independent effect on musculoskeletal pain in our study after adjusting for other covariates, which was in contrast to the findings of an earlier study among blue collar workers in which significant positive associations were found for pain in the shoulder, neck, and low back. ${ }^{15}$

Poor support from both supervisors and colleagues at work have been reported to be risk factors for musculoskeletal disorders in cross-sectional as well as longitudinal surveys. $^{14} 40$ In our study, the only positive association was between poor instrumental support from supervisors and pain in the wrists/hands. It was possible that workers having high social support from supervisors might be assigned to 
work in more favourable working environments and hence less exposed to physical hazards.

Coping style, in particular eating behaviour, was important in predicting musculoskeletal pain. Current drinking was significantly related to pain in the elbow, wrists/hands, and hips/thighs. Unlike the findings in the previous studies, ${ }^{41-46}$ we did not find an association between smoking and musculoskeletal pain in this study. This might be due to the multiple collinearity between smoking and drinking and the "eating behaviour" coping style, as the latter was a complex variable composed of four items: eating, drinking alcohol, drinking tea/coffee, and smoking. Other coping styles, "escaping/abreaction", "external/social", and "internal" were also found to have an impact on pain in different body regions.

\section{Limitations and strengths of the study}

The cross-sectional nature of the study did not allow a clear causal relation between psychosocial factors and musculoskeletal pain to be established. Underreporting of health problems by the workers was possible for fear of redeployment on-shore, with the consequent decrease in earnings. The lack of objective assessment of physical exposures might be a concern, ${ }^{17}$ although perceived stress from "physical environment of workplace" and "ergonomics" could have provided some subjective assessments of the physical risk factors at work. The inclusion of job type in the regression modelling did provide a surrogate for physical exposure, albeit rather crude, as there would be a degree of overlap between the job titles and the physical tasks involved. On the whole, we can only say that psychosocial variables/occupational stress "may influence" musculoskeletal pain, but their actual effect will remain unknown until adequate physical exposure assessment is included. In designing the questionnaire, we sought suggestions from a panel of doctors who worked on the platforms for any additional occupational stressors that were not included in the original questionnaire for UK offshore oil workers. No additional stressors were added as a result of the consultation. Hence some other psychosocial factors identified in previous studies on musculoskeletal problems in other occupational groups could have been omitted in our study. The associations between musculoskeletal pain and psychosocial factors were separately analysed by nine body regions and this could increase the risk of significant associations caused by chance. Hence, these associations should be viewed at a more macroscopic level, emphasising the consistency of association across different body regions, rather than the specific associations for the nine different outcomes.

Although we studied only half of the offshore workers in the company there is no reason to believe they were not an unbiased sample of the whole population of installation workers and hence the results can be generalised. The occupational stress scale (OSS) was based on Cooper and colleagues' occupational stress theory and their relevant research on offshore oil workers at North Sea oilfields in the $\mathrm{UK}^{24}$ and has been proven to be a valid and reliable tool for measuring occupational stress. ${ }^{26}$ Other psychosocial factorstype A behaviour personality, social support, and coping style-were included, and subscales of these were used in the data analyses. This enabled us to explore the intrinsic relations between the specific traits of the scales with the health outcomes. We performed sensitivity testing by redefining social support to include both "often" and "sometimes" responses and found only minor changes occurring in three symptoms (results not shown), suggesting that our results were quite robust. Major potential confounding factors were controlled in the analyses of the associations between psychosocial factors at work and musculoskeletal pain.

Subject to the limitation in physical exposure assessment the findings of this study infer that perceived work stress, maladaptive coping style, alcohol drinking, and poor social support at work are associated with musculoskeletal pain across a range of body regions. These observations support the widely accepted biopsychosocial model of musculoskeletal disorders ${ }^{47}$ and suggest that in future studies of work related musculoskeletal disorders, psychosocial factors must be given due consideration.

\section{ACKNOWLEDGEMENTS}

The authors would like to thank the Worker's Hospital of the West Company of South Sea of the Chinese Off-shore Oil Company for supporting this study.

\section{Authors' affiliations}

W Q Chen, Department of Biostatistics and Epidemiology, College of Public Health, Sun Yat-sen University, Guangzhou, China

I T-S Yu, T W Wong, Department of Community \& Family Medicine, The Chinese University of Hong Kong, Hong Kong SAR, China

Competing interests: none declared

\section{REFERENCES}

1 Keyserling WM. Workplace risk factors and occupational musculoskeletal disorders, Part 1: A review of biomechanical and psychophysical research on risk factors associated with low-back pain. Am Ind Hyg Assoc J 2000;61:39-50.

2 Devereux JJ, Buckle PW, Vlchonikolis IG. Interactions between physical and psychosocial risk factors at work increase the risk of back disorders: an epidemiological approach. Occup Environ Med 1999;56:343-53.

3 Engström T, Hanse JJ, Kadefors R. Musculoskeletal symptoms due to technical preconditions in long cycle time work in an automobile assembly plant: a study of prevalence and relation to psychosocial factors and physical exposure. Appl Ergon 1999;30:443-53.

4 van der Windt DAW, Thomas E, Pope DP, et al. Occupational risk factors for shoulder pain: a system review. Occup Environ Med 2000;57:433-42.

5 Riihimaki H. Low back pain, its origin and risk indicators. Scand J Work Environ Health 1991;17:81-90.

6 Hoogendoorn WE, van Poppel MN, Bongers PM, et al. Physical load during work and leisure time as risk factors for back pain. Scand J Work Environ Health 1999;25:387-403.

7 Ferguson S, Marras WA. Literature review of low back disorders surveillance measures and risk factors. Clin Biomech 1997;12:211-26.

8 Burdof A, Sorock G. Positive and negative evidence of risk factors for back disorders. Scand J Work Environ Health 1997;23:243-56.

9 Ariens GA, van Mechelen W, Bongers PM, et al. Physical risk factors for neck pain. Scand J Work Environ Health 2000;26:7-19.

10 Jensen LK, Eenberg W. Occupation as a risk factor for knee disorders. Scand J Work Environ Health 1996;22:165-75.

11 Houtman ILD, Bongers PM, Smulders PGW, et al. Psychosocial stressors at work and musculoskeletal problems. Scand J Work Environ Health 1994;20:139-45.

12 De Zwart BCH, Broerson JPJ, Frings-Dresen MHW, et al. Repeated survey on changes in musculoskeletal complaints relative to age and work demands. Occup Environ Med 1997; 54:793-9.

13 Leino P. Symptoms of stress predict musculoskeletal disorders. J Epidemiol Commun Health 1989;43:293-300.

14 Ahlberg-Hultén GK, Theorell T, Sigala F. Social support, job strain and musculoskeletal pain among female health care personnel. Scand J Work Environ Health 1995;21:435-9.

15 Flodmark BT, Aase G. Musculoskeletal symptoms and type A behavior in blue collar workers. Br J Ind Med 1992;49:683-7.

16 Esterlander AM, Takala EP, Viikari-Juntura E. Do psychological factors predict changes in musculoskeletal pain? J Occup Environ Med 1998;40:445-53.

17 Bonger PM, Winter CRV, Kompier MAJ, et al. Psychosocial factors at work and musculoskeletal disease. Scand J Work Environ Health 1993;19:297-312.

18 Carayon P, Smith MJ, Haims MC. Work organization, job stress, and workrelated musculoskeletal disorders. Hum Fact 1999;41:644-66.

19 Sutherland VJ, Cooper CL. Occupational stress in the offshore oil and gas industry. Int Rev Ergon 1989;2:183-215.

20 Sutherland VJ, Flin RH. Stress at sea: a review of working conditions in the offshore oil and fishing industries. Work Stress 1989;3:269-85.

21 Parkes KR. Psychosocial aspects of stress, health and safety on North Sea installations. Scand J Work Environ Health 1998;24:321-33.

22 Norman JN, Ballantine BN, Brebner JA, et al. Medical evacuations from offshore structures. Br J Ind Med 1988;45:619-23.

23 Cooper CL, Sloan SJ, Williams S. Occupational stress indicator management guide. Oxford: NFER-Nelson Publishing Company Limited, 1988:56-64. 
24 Cooper CL, Sutherland VJ. Job stress, mental health, and accidents among offshore workers in the oil and gas extraction industries. J Occup Med 1987;29:1 19-25

25 Sutherland VJ, Cooper, CL. Stress in the offshore oil and gas exploration and production industries: an organizational approach to stress control. Stress Med 1996; 12:61-78

26 Chen WQ, Wong TW, Yu TS. Reliability and validity of the occupational stress scale for Chinese off-shore oil installation workers. Stress Health 2001; 17:175-83.

27 Powell TJ, Enright SJ. Anxiety and stress management. London: New York, 1990: 1-21

28 Edwards JR, Baglioni Jr AJ, Cooper CL. The psychometric properties of the Bortner type A scale. Br J Psychol 1990;81:315-33.

29 Cooper CL, Payne R. Personality and stress: individual differences in the stress process. Chichester: John Wiley \& Sons, 1991:151-80.

30 Hingley P, Cooper CL. Stress and the nurse manager. Chichester: John Wiley \& Sons, 1986:209-26.

31 Jonsson KB, Kilbom A, Vinterberg A, et al. Standardized Nordic questionnaires for the analysis of musculoskeletal symptoms. Appl Ergon 1987; 18:233-7.

32 Munro BH. Statistical methods for health care research, 3rd edn. Philadelphia: Lippincott, 1997:310-40.

33 Wong TW, Chen WQ, Yu TS, et al. Perceived sources of occupational stres among Chinese off-shore oil installation workers. Stress Health 2002; 18:217-26.

34 Hildebrandt VH, Bongers PM, Daul J, et al. Identification of high-risk groups among maintenance workers in a steel company with respect to musculoskeletal symptoms and workload. Ergonomics 1996;39:232-42

35 Thomas MC, John CR, Chris LA. Work-related musculoskeletal disorders in bricklaying: a symptom and job factors survey and guidelines for improvements. Appl Occup Environ Hyg 1996;11:1335-9.
36 Krause N, Ragland DR, Greiner BA, et al. Physical workload and ergonomic factors associated with prevalence of back and neck pain in urban transit operators. Spine 1997;22:2117-27.

37 Torp S, Riise T, Moen BE. How the psychosocial work environment of motor vehicle mechanics may influence coping with musculoskeletal symptoms. Work Stress 1999;13:193-203.

38 Ohlsson K, Hansson GA, Balogh I, et al. Disorders of the neck and upper limbs in women in the fish processing industry. Occup Environ Med 1994:51:826-83.

39 Skov T, Borg V, Ørhede E. Psychosocial and physical risk factors for musculoskeletal disorders of the neck, shoulders, and lower back in salespeople. Occup Environ Med 1996;53:351-6.

40 Toomingas A, Theorell T, Michélsen $\mathrm{H}$, et al. Associations between self-rated psychosocial work conditions and musculoskeletal symptoms and signs. Scand J Work Environ Health 1997;23:130-9.

41 Boshuizen HC, Verbeek JHAM, Broerson JPJ, et al. Do smokers get more back pain? Spine 1992;18:35-40

42 Feldman DE, Rossignol $M$, Shrier I, et al. Smoking-A risk factor for development of low back pain in adolescents. Spine 1999;24:2492-6.

43 Goldberg MS, Scott SC, Mayo NE. A review of the association between cigarette smoking and the development of nonspecific back pain and related outcomes. Spine 2000;25:995-1014.

44 Leboeuf-Yde C, Kyvik KO, Bruun NH. Low back pain and lifestyle. Part I: smoking. Information from a population-based sample of 29,424 twins. Spine 1998;23:2207-14

45 Leboeuf-Yde C. Smoking and low back pain: a systematic literature review of 41 journal articles reporting 47 epidemiologic studies. Spine 1999:24:1463-70.

46 Scott SC, Goldberg MS, Mayo NE, et al. The association between cigarette smoking and back pain in adults. Spine 1999;24:1090-8.

47 Feyer AM, Herbison P, Willianson AM, et al. The role of physical and psychological factors in occupational low back pain: a prospective cohort study. Occup Environ Med 2000;57:1 16-20. 